\title{
The Digital Educational Environment: The Problem of Its Accessibility for Visually Impaired Students
}

\author{
https://doi.org/10.3991/ijet.v16i16.23453 \\ Albina Bilyalova $\left.{ }^{\bowtie}\right)$, Liliya Bazarova, Daniya Salimova, Gulchachak Patenko \\ Kazan (Volga Region) Federal University, Kazan, Russia \\ abill71@mail.ru
}

\begin{abstract}
The changes taking place in recent decades in the humanitarian sphere of the life of Russian society are manifested in the increased attention to problems of social integration of people with disabilities. The social state policy concerning such people is increasingly focused on creating equal opportunities so as to participate in the life of society and get involved in socially useful activities. One of the most important aspects of equal opportunities for the visually impaired is ensuring the access to information and opportunity to participate in public information exchange. The process of society informatization makes the solution of these problems even more urgent. In this regard, the wide distribution of digital electronic resources is of particular importance, taking into account the requirements for the visually impaired and computer technology. In the given research there substantiated possibilities of using digital educational resources, computer typhlotechnologies when interacting with the information public. Such results can be implemented in the organization of both academic and corporate education. The developed approaches can be used by various groups of developers to create their own digital educational environment.
\end{abstract}

Keywords-information exchange, digital electronic resource, digital educational environment, computer tiflotechnology, the visually impaired, professional education.

\section{Introduction}

Information systems in education began to be used in the middle of the 20th century and have evolved from simple educational applications and information sites to complex software systems. Despite the demand for information systems in education, several publications indicate a lack of flexibility in their work since information educational environment (IEE) forces their users to work according to predefined processes with fixed data formats which reduce the degree of individualization and variability of approaches to training organization [33]. This entails a decrease in the number of users of these systems and the reluctance of participants in the educational process to switch to them.

The solution to the problem of ensuring the required flexibility of the new generation of IEE is the use of digital educational environment, systems, and tools that con- 
tribute to improving the efficiency and quality of education, individualization, personalization, and adaptability of learning, self-realization of all participants in the educational process [5], [34]. Digital educational environment implements user modeling - the presentation in a form that reflects his current state in terms of the environment (the general level of competence, the status of training, etc.). It includes tools for managing knowledge, education in general as well as tools for collecting and analyzing data; it analyzes the needs of the student, proposing scenarios for his further development.

In the context of global informatization of society, the quality of life and social status of an individual is largely determined by the possibility of active participation in public information exchange - prompt access to the necessary information, it's processing and presenting the results of their information activities. For the visually impaired the participation in the process of public information exchange is complicated by the mismatch of their perception capabilities and the established social practice, focused mainly on visual forms of information presentation [30]. Traditional ways of access to information resources by the visually impaired based on an alternative material representation (the sound on magnetic media or relief-point on paper in Braille) require significant time and material costs and it cannot provide adequate information needs to the modern level of development of society in various spheres of human activity (educational, professional, etc.).

In 1993, the UN General Assembly adopted the "Standard Rules for the Equalization of Opportunities for People with Disabilities", which implies serious moral, political, and economic obligations of states towards people with disabilities.

As one of the most effective means of ensuring the participation of the visually impaired in public information exchange can be computer typhlotechnologies which with special hardware and software make the use of general-purpose computer equipment and most standard user capabilities available to the blind and visually impaired. As a result, people with visual impairment receive an effective tool for free independent access to public information resources. The massive distribution and significant reduction in the cost of computer technology make the use of computer technology even more relevant. A necessary condition for success of the educational and further professional activity of the blind and visually impaired is the possibility of free operational information exchange, and, consequently, the development of computer technology as a tool for its provision.

Thus, currently the process of typhoid computerization acquires high social significance as one of the most important factors in the social integration of people with visual impairment.

\section{Methods}

The general problems of integration of people with disabilities into society are considered in the works of different social scientists and psychologists [1], [6-13], [1618], [20-24], [29]. Much attention is paid to problems generated not by specific restrictions on life, but by special socio-cultural status of the disabled. The psychophys- 
iological and cognitive characteristics of the blind and visually impaired, mechanisms of compensation for visual defects are revealed in the works of [3-5], [15], [31-32]. Among the most significant works devoted to social adaptation, organization of rehabilitation work, and integration into the modern society of visually impaired people, it is necessary to note the works of typhlo educators [2], [23].

Scientists all over the world are actively engaged in theoretical and applied research on possibilities and conditions of using computer technologies as a tool for improving the system of special education. Scientists developed conceptual ideas in the field of philosophy of computerization of special education. It is shown that the defectological meaning of the use of computer technologies consists in the development of new "workarounds" of education as well as in the creation of computermediated pedagogical technologies [11], [25-28].

The problem of providing access to information for visually impaired people is traditionally solved by library services. The beginning of the scientific development of the problems of information services for the blind and visually impaired through libraries was laid in the 1960s. A great contribution to the theoretical understanding of this problem was made by K. A. Kuzoro and A. A. Lyapkova, M. V. Nazarov [14], [19]. A study of the needs of readers in the use of digital educational resourcesinformation resources typhlo. In this regard, a survey was conducted among the visually impaired (mainly students and specialists). All participants highly appreciated the importance of computer technologies and electronic information for the educational, labor and cultural development of the blind. As a result of the study, the authors came to the conclusion that ensuring equal opportunities for the visually impaired is a fundamental principle of library service, and also analyzed the conditions for its implementation in library practice.

The problems of the development and implementation of modern digital centers, typhlo informational technologies occupy one of the central places at all scientific and practical conferences: "The role of computer technologies in the intellectual work of the blind. Prospects for development and application" (N. Novgorod), "Professional education of visually impaired people: problems, experience, prospects" (Moscow), etc.

The following methods were used to implement the goals and objectives of this study: data analysis methods (the retrospective analysis of scientific literature, content analysis of periodicals and materials of scientific and practical conferences on the research problem), methods of mathematical statistics; empirical methods (observation); diagnostic methods (interview, questionnaire).

\section{$3 \quad$ Results and Discussions}

The activity of visually impaired people in the computer field is proved by quite numerous Internet resources developed and maintained by them, including several working mail forums devoted to various problems of visually impaired people. 
The given article touches upon the ways of using computer technologies adapted for visually impaired people to provide them with the opportunity to interact with the information environment of society effectively.

The first approach to providing access to computer equipment for visually impaired people is to create a special computer for them, which has built-in means that provide speech, information output and special software developed with non-visual access. The main disadvantage of this approach is the non-standard equipment and programs, which generate high prices and difficulties in operation.

Currently, the integrated form of computer hardware is used mainly in creating various portable computer devices for the impaired, but they have not become widespread in Russia yet.

Another the most promising and widespread approach is in additional hardware and software for bump-point and sound output to compensate for the visually impaired when working with an ordinary personal computer and general-purpose programs (MS Word, Internet Explorer, etc.). As a result, the blind and visually impaired receive user experiences that are largely similar to those of users with normal vision [30].

The special device called the Braille display is used for raised dots of computer information. This is a line, usually containing from twenty to eighty modules, on which computer information is displayed. Conventionally, work with the Braille display can be represented as follows: a blind person "sees" a computer screen through a small window and, by moving it, gets sequential access to screen information.

At the present stage of development of computer technologies software speech synthesizers are used for voice output which convert textual computer information into acoustic signals recognized by the listener as speech. The development of software speech synthesis allowed people with impaired vision to use a computer without the use of additional specialized hardware and thereby ensured the massive availability and distribution of computer technologies for blind users.

The most effective conditions for a blind user to work on a computer is created by the joint use of a speech synthesizer and the Braille display. However, the high cost of Braille displays significantly reduces their usability. Many blind people work on a computer, using only the means of speech output, and even in this case, the computer becomes an effective tool for ensuring information exchange between the blind and the surrounding society.

The main tool for a blind user to control a computer is a regular keyboard. Practice has shown that if visual impairment is not accompanied by additional disorders of the motor system, mastering the keyboard does not cause great difficulties, and mastering the ten-finger touch typing method can significantly increase the speed of work.

The main features of the workflow of a blind user are determined by the information model of the operating situation. The operating situation in visual access is modeled through an image on the screen that provides the user with an entire view of the system state (running applications, current operating mode of the active application, etc.). The user's interaction with the working environment is organized by means of visible elements (menus, buttons, etc.), which are also displayed on the screen and provide the corresponding functions with the mouse. 
In terms of non-visual access, the information model of the operating situation does not have a material carrier. It is synthesized by a blind user's mind on the basis of a series of sequential messages displayed on a Braille display or a speech synthesizer. At the same time, to provide an idea of the workflow state and the ability to manage it a special organization of the information flow is needed, including recoding and highlighting the most significant part of information. This task is handled by a screen reader. In addition, the blind cannot use a mouse; they must control the computer using keyboard commands.

The study developed a set of knowledge and skills that increase its efficiency based on the analysis of the workflow without visual control (detailed algorithmic study of ways to perform the required practical actions on a computer, mastery of working with standard controls via a keyboard, etc.).

Computer hardware technologies also include means that make it possible to use the residual vision of the visually impaired to access computer information effectively. These are various software tools for enlarging the screen image and increasing its contrast.

Thus, specialized digital educational resources, computer tiflotechnologies are effective means of ensuring the participation of the visually impaired in public information exchange. Their use expands possibilities of educational and professional activities of the blind and visually impaired and contributes to their integration into modern society. In addition to common goals for the entire process of computerization, typhoid computerization has an additional compensatory load, i.e. leveling difficulties caused by visual impairment in the field of public information exchange and thereby providing the visually impaired with real opportunities to participate in various types and forms of socio-cultural life (including education and professional activity) equally with the rest of society. This determines the significance of typhlocomputerization as a factor of social integration of the visually impaired.

\section{$4 \quad$ Summary}

The competent use of the means of access to a computer provides the blind and visually impaired with user capabilities that do not fundamentally differ from those of users with normal vision (except for working with graphical non-textual information). The main source of peculiarities and difficulties of the workflow is the need to build a general idea of its state based on sequential local information messages. Overcoming specific difficulties and increasing the efficiency of the work of the visually impaired is facilitated by the development of the set of special knowledge and skills proposed in this work.

The survey of the visually impaired was conducted in the Tatar regional organization of the Russian Society of the Blind in Naberezhnye Chelny city to study the situation in the field of application of specialized programs, such as typhoid computerization. It is estimated that computer users make up about $10 \%$ of people with this type of disability of working age. They use a computer in educational, labor, and social activities and note as the main results of typhoid computerization: broadening their 
horizons ( $81.8 \%$ of respondents), facilitating access to information of an educational or professional nature $(74.2 \%)$, promptness of obtaining information $(72,7 \%)$, an increase in confidence in their capabilities $(68.2 \%)$.

It is significant that among the blind and visually impaired (age 16-18), more than half consider themselves to be computer users. Everyone without exception is planning to use a computer in the future.

$73.9 \%$ of the respondents consider the use of computer typhlotechnologies, digital educational resources useful for all people with visual impairment, which indicates understanding the significance of the typhlocomputing process.

The majority of the respondents $(95.8 \%)$ consider it useful to create specialized computer centers or programs for the visually impaired people, expecting to receive advice and technical support there as well as access to expensive technical equipment.

Among reasons why they do not use computer equipment, the respondents most often cite the lack of computer equipment availability (35.8\%). Secondly, the lack of necessary knowledge and skills (26.4\%). The need for computer training is also expressed by the majority of blind and visually impaired users.

The results of the study demonstrated the demand for typhoid computerization by the visually impaired, a high subjective assessment of the effectiveness of the use of computer typhoid technologies, digital educational resources as well as the need for educational, methodological and technical support of this process.

The use of computer technology, contributing to the versatile personal development of the blind and visually impaired and expanding possibilities of their full participation in various spheres of social and cultural life creates favorable conditions for the social integration of the visually impaired.

\section{Conclusion}

The qualified use of specialized digital educational resources, computer typhlotechnologies provides the visually impaired with new opportunities: access to information on electronic media, including information resources on the Internet; access to flat-print texts (by scanning and recognition); transformation of electronic information into an accessible and convenient material form of presentation (printing text in relief-point or enlarged font); independent preparation of various documents on a computer (study papers, reports, etc.); the use of modern generally accepted software tools for working with information (information retrieval systems, databases, etc.).

Thus, the competent use of computer hardware technologies to a significant extent compensates for the lack of vision in the field of public information exchange: it provides opportunities for activities, it increases the accessibility of the public information environment, it is a universal means for transforming the forms of information presentation, and, as a result, it expands the possibilities of educational, professional and social activities of the visually impaired and promotes their true integration into modern society. 


\section{$6 \quad$ References}

[1] E. A. Averina and A. V. Popova, "evaluation of environment accessibility for people with disabilities in novosibirsk," Vestnik Tomskogo Gosudarstvennogo Universiteta-FilosofiyaSotsiologiya-Politologiya-Tomsk State University Journal of Philosophy Sociology and Political Science, vol. 33, no. 1, pp. 5-14, Mar 2016. https://doi.org/10.17223/1998863x $\underline{133 / 1}$

[2] V. P. Bhujbal, K. K. Warhade, and Ieee, Hand sign recognition based communication system for speech disable people (Proceedings of the 2018 Second International Conference on Intelligent Computing and Control Systems). 2018, pp. 348-352. https://doi.org/ 10.1109/iccons.2018.8663054

[3] B. Bilge, "'Accessibility" in Housing Design for People Who Are Blind," 4th International Conference on Education and Social Sciences (Intcess 2017), pp. 235-249, 2017.

[4] A. M. Brock, P. Truillet, B. Oriola, D. Picard, and C. Jouffrais, "Interactivity Improves Usability of Geographic Maps for Visually Impaired People," Human-Computer Interaction, vol. 30, no. 2, pp. 156-194, Mar 2015. https://doi.org/10.1080/07370024.2014.924412

[5] A. Crudden, J. M. Giesen, and Z. Sui, "Contrasting competitively employed and unemployed VR applicants with visual disabilities: Characteristics and VR service delivery patterns," Journal of Vocational Rehabilitation, vol. 49, no. 1, pp. 117-126, 2018. https://doi. org/10.3233/jvr-180958

[6] T. Curran et al., "Disabled young people's hopes and dreams in a rapidly changing society: a co-production peer research study," Disability \& Society. https://doi.org/10.1080 /09687599.2020.1755234

[7] R. L. de Queiroz, J. M. dos Santos, L. S. da Silva, and D. J. G. Coutinho, "challenges and possibilities of the inclusive school for persons with disabilities," Revista Inclusiones, vol. 5, pp. 124-140, Oct-Dec 2018.

[8] J. A. S. Gomez, "Experience of a student with visual disability in the spanish educational system," Revista De Educacion Inclusiva, vol. 11, no. 2, pp. 117-137, Dec 2018.

[9] I. Hurjui and C. M. Hurjui, "General considerations on people with disabilities," Romanian Journal of Legal Medicine, vol. 26, no. 2, pp. 225-228, Jun 2018.

[10] J. Jadan-Guerrero, I. Altamirano, H. Arias, and J. Jadan, "Designing Assistive Technologies for Children with Disabilities: A Case Study of a Family Living with a Daughter with Intellectual Disability," in Technologies and Innovation, vol. 658, R. ValenciaGarcia, K. LagosOrtiz, G. AlcarazMarmol, J. DelCioppo, and N. VeraLucio Eds., (Communications in Computer and Information Science, 2016, pp. 254-268. https://doi.org/10.1007/978-3$\underline{319-48024-4 \_20}$

[11] N. Kaklanis, G. Stavropoulos, and D. Tzovaras, "Modeling people with motor disabilities to empower the automatic accessibility and ergonomic assessment of new products," Applied Ergonomics, vol. 51, pp. 120-136, Nov 2015. https://doi.org/10.1016/j.apergo. 2015.04.016

[12] N. Khanlou, A. Khan, L. M. Vazquez, and M. Zangeneh, "Digital Literacy, Access to Technology and Inclusion for Young Adults with Developmental Disabilities," Journal of Developmental and Physical Disabilities, vol. 33, no. 1, pp. 1-25, Feb 2021. https://doi.org/ 10.1007/s10882-020-09738-w

[13] A. Kruszewska, "integration of children with disabilities in an integrative preschool," in 11th International Conference of Education, Research and Innovation, L. G. Chova, A. L. Martinez, and I. C. Torres Eds., (ICERI Proceedings, 2018, pp. 9203-9212.

[14] K. A. Kuzoro and A. A. Lyapkova, "service of the readers with disabilities in municipal rural libraries of tomsk region: analysis of the experience," Vestnik Tomskogo Gosudar- 
stvennogo Universiteta-Kulturologiya I Iskusstvovedenie-Tomsk State University Journal of Cultural Studies and Art History, vol. 24, no. 4, pp. 222-233, Dec 2016. https://doi.org/ $\underline{10.17223 / 22220836 / 24 / 25}$

[15] Y. Leyser, A. Heinze, and G. Kapperman, "Stress and adaptation in families of children with visual disabilities," Families in Society-the Journal of Contemporary Human Services, vol. 77, no. 4, pp. 240-249, Apr 1996. https://doi.org/10.1606/1044-3894.905

[16] M. Manzoor and V. Vimarlund, "Digital technologies for social inclusion of individuals with disabilities," Health and Technology, vol. 8, no. 5, pp. 377-390, Nov 2018. https://doi.org/10.1007/s12553-018-0239-1

[17] E. Martinez Amador, "Deaf People do not Go to the Movies: Accessibility for People with Hearing Disabilities in the Spanish Cinema," Fonseca-Journal of Communication, no. 12, pp. 130-144, 2016.

[18] S. Muddle, J. McElwee, R. Vincent, N. Birdsey, and L. Best, "Talking with parents of children with learning disabilities: Parents' ideas about the Circle of Security parenting programme," British Journal of Learning Disabilities. https://doi.org/10.1111/bld.12371

[19] M. V. Nazarov, "The libraries and people with physical disabilities. The study findings," Nauchnye I Tekhnicheskie Biblioteki-Scientific and Technical Libraries, no. 8, pp. 51-62, 2020. https://doi.org/10.33186/1027-3689-2020-8-51-62

[20] Z. Oborenko and B. Rivza, "legal and policy framework of employment for people with disabilities in latvia," in Economic Science for Rural Development, vol. 49, A. Auzina Ed., (Economic Science for Rural Development, 2018, pp. 372-384. https://doi.org/10.22616/ $\underline{\text { esrd.2018.156 }}$

[21] L. Olivier, P. Sterkenburg, and E. van Rensburg, "The effect of a serious game on empathy and prejudice of psychology students towards persons with disabilities," African Journal of Disability, vol. 8, Mar 2019, Art no. a328. https://doi.org/10.4102/ajod.v8i0.328

[22] S. Pegg, M. Karl, and P. Harpur, "Negotiating work-based travel for people with disabilities," Current Issues in Tourism. https://doi.org/10.1080/13683500.2020.1801605

[23] D. I. Prisiazhniuk, "the social well-being of families of children with disabilities in contemporary russia," Tomsk State University Journal, no. 437, pp. 93-103, Dec 2018. https://doi.org/10.17223/15617793/437/14

[24] Salwa Abdullah Al Majali, "The Digital World for Children and its Relationship with Personality Disorders: Exploring Emerging Technologies", in International Journal of Emerging Technologies in Learning (iJET) Vol. 15, No. 01, pp. 213-221, 2020. https://doi.org/ $\underline{10.3991 / i j e t . v 15 i 01.11412}$

[25] M. C. Saleh and S. M. Bruyere, "Leveraging Employer Practices in Global Regulatory Frameworks to Improve Employment Outcomes for People with Disabilities," Social Inclusion, vol. 6, no. 1, pp. 18-28, 2018. https://doi.org/10.17645/si.v6i1.1201

[26] J. A. Sandoval-Bringas, M. Carreno-Leon, M. A. Espiritu, O. J. Lopez-Martinez, M. Sandoval-Carreno, and J. J. H. Alonso, Design of a multifunctional electronic module adaptable to a motorized wheelchair for people with motor disabilities (2019 International Conference on Inclusive Technologies and Education). 2019, pp. 201-204. https://doi.org/10.1109/contie49246.2019.00046

[27] D. Segev and M. Schiff, "Integrating Israeli Defense Force (IDF) veterans with disabilities into the workforce: characteristics and predictors," Israel Journal of Health Policy Research, vol. 8, no. 1, Dec 2019, Art no. 86. https://doi.org/10.1186/s13584-019-0352-2

[28] M. Sepulchre and R. Lindqvist, "Enhancing active citizenship for persons with psychosocial disabilities," Scandinavian Journal of Disability Research, vol. 18, no. 4, pp. 316-327, 2016. https://doi.org/10.1080/15017419.2015.1105288 
[29] N. Y. Sun, "On the Road to Equal Enjoyment of Human Rights for Persons with Disabilities: The Development of Domestic Laws in Taiwan and Their Dialogue with the CRPD," in Taiwan and International Human Rights: a Story of Transformation, J. A. Cohen, W. P. Alford, and C. F. Lo Eds., (Economics Law and Institutions in Asia Pacific, 2019, pp. 661678. https://doi.org/10.1007/978-981-13-0350-0_37

[30] Z. W. Taylor, "Clicking in the Dark: Are Student Financial Aid Websites Accessible for Students with Disabilities?," Journal of Student Financial Aid, vol. 49, no. 2, 2020, Art no. 2.

[31] B. Trebicka-Postrzygacz, A. Roguska, and A. Antas-Jaszczuk, "from exclusion to inclusion of people with disabilities," in 11th International Conference of Education, Research and Innovation, L. G. Chova, A. L. Martinez, and I. C. Torres Eds., (ICERI Proceedings, 2018, pp. 4869-4874. https://doi.org/10.21125/iceri.2018.0211

[32] R. Virbaliene and I. Baranauskiene, "pecularities of transition of young people with disabilities to adult life," in Society, Integration, Education, Vol Iii: Special Pedagogy Social Pedagogy Innovation in Language Education, V. Lubkina, S. Usca, and A. Zvaigzne Eds., (Sabiedriba Integracija Izglitiba-Society Integration Education, 2018, pp. 179-189. https://doi.org/10.17770/sie2018vol1.3380

[33] Zheng, Yuhui Yang, Huifang Chai, Mo Chen, Jianping Zhang, "The Development and Performance Evaluation of Digital Museums Toward Second Classroom of Primary and Secondary School - Taking Zhejiang Education Technology Digital Museum as An Example", in International Journal of Emerging Technologies in Learning (iJET) Vol. 14, No. 2, pp. 69-84, 2019. https://doi.org/10.3991/ijet.v14i02.7897

[34] Wahyu Djoko Sulistyo, Moch. Nurfahrul Lukmanul K, Bayu Kurniawan " The Development of 'JEGER' Application Using Android Platform as History Learning Media and Model" in International Journal of Emerging Technologies in Learning (iJET) Vol. 15, No. 07, pp. 110-122, 2020. https://doi.org/10.3991/ijet.v15i07.11649

\section{$7 \quad$ Authors}

Albina Anvarovna Bilyalova is a Dr. of Philology, Professor and Head of the Department of Philology at Naberezhnye Chelny Institute (branch) of Kazan Federal University, Russia. Dr. Bilyalova's research concentrates on innovative methods in pedagogy, language dynamics, and the impact of Internet discourse on language development. Her academic interests are also in problems of accessibility of the digital educational environment of higher education for students with disabilities.

Daniya Abuzarovna Salimova is a Dr. of Philology, Professor and a leading specialist in the field of Russian studies, comparative linguistics, sociolinguistics, cultural linguistics. Dr. Salimova's research concentrates on cultural linguistics; language categories and units in the Russian text space; problems of digital transformation in Education and Higher Education in digital age.

Liliya Vyazirovna Bazarova is a PhD candidate of Philology, Associate Professor of the Department of Philology at Naberezhnye Chelny Institute (branch) of Kazan Federal University, Russia. The major is comparative, historical, typological and comparative linguistics. Scientific interests are comparative linguistics, phraseology, scientific and technical translation, neurolinguistics, intercultural communication, medical terminological system, the digital educational environment of higher educa- 
tion for students with disabilities. The reviewer in an international peer-reviewed journal "Horizon Research Publishing Linguistics and Literature Studies".

Gulchachak Rinatovna Patenko is a PhD candidate of Philology, Associate Professor of the Department of Philology at Naberezhnye Chelny Institute (branch) of Kazan Federal University, Russia. Scientific interests are philology, education, PR, advertising, the digital educational environment of higher education for students with disabilities.

Article submitted 2021-04-21. Resubmitted 2021-05-22. Final acceptance 2021-05-22. Final version published as submitted by the authors. 